$* * *$ Reprinted with permission. No further reproduction is authorized without written permission from the Human Kinetics. This version of the document is not the version of record.

Figures and/or pictures may be missing from this format of the document.***

\title{
A Theoretical Conceptualization for Motivation Research in Physical Education: An Integrated Perspective
}

\begin{abstract}
Ang Chen
This paper is intended to conceptualize motivation research in physical education from an integrated perspective in that the motivation research and its findings are situated in the dynamics of teaching and learning. Major motivation theories and research findings are reviewed, synthesized, and critiqued. The synthesis shows that a dominant number of motivation research studies have been based on achievement goal theories. An emerging line of research relies on the theoretical framework of interest. In most studies, motivation is conceptualized as individual psychological dispositions rather than a process of learner-content interaction in the context defined by the curriculum. The synthesis also revealed that the findings are limited because learning achievement was loosely or not at all defined in most investigations. An integrated conceptual framework for future research is proposed to link motivation to specific achievement settings, to the physical education curriculum, and to the socioeconomic environment within and beyond the school.
\end{abstract}

Motivation has been viewed as a key factor influencing learning outcomes. High learning achievements often are attributed to high motivation in the student and a learning environment that nurtures high motivation. Conversely, failure in achieving academic goals is considered resulting from low student motivation and factors that demotivate students. According to Pintrich and Schunk (1996), the term "motivation" originates from the Latin verb movere (to move); it is something that "gets us going, keeps us moving, and helps us get jobs done" (p. 4). Defined from the current cognitive perspective, therefore, motivation is the process in which "goal-directed activity is instigated and sustained" (p. 4). In this sense, motivation

The author<ac192@umail.umd.edu> is with the Department of Kinesiology at the University of Maryland, College Park, MD 20742. 
also can be described as the internal process that gives behavior its energy and direction (Reeve, 1996).

This internal process is often affected by personal and environmental factors that are associated with engagement of an activity and rewards/punishment for the engagement (Stipek, 1996). In general, the purpose of motivational research is to examine the effects of personal and environmental factors on the internal process of motivation that, in turn, energizes and directs behavior. In educational settings, research on motivation is mainly concerned with how personal and environmental factors involved in the teaching/learning process energize (or deenergize) and direct (or misdirect) student learning. From this perspective, motivation can be operationalized as an observable process of getting students to learn. This process is reflected in individual students' responses to difficulties, problems, failures, and setbacks in their pursuit of an achievement-oriented activity such as solving a mathematical problem or learning tennis strokes. Behavioral responses, in this sense, are a valid motivation indicator (Pintrich \& Schunk, 1996).

In the last decade, motivation research has extended to the domain of school physical education and has generated informative findings. This paper is intended to search for a better understanding of these findings. Particularly, this paper attempts to (a) review and evaluate motivation research related to student learning, (b) interpret and critique research findings in terms of their meaningfulness to teaching and learning, and (c) explore and articulate theoretical conceptualizations for future motivation research in physical education. After a brief overview of theoretical articulation of motivation sources, the focus will be on reviewing and critiquing studies on effects of personal and environmental factors on motivation to learn in physical education. Lastly, an integrated theoretical perspective for motivation research is proposed.

I adopt a perspective that integrates motivation research within the pedagogical context of learning. Based on this perspective, advances made and issues that have evolved in motivation research are interpreted, critiqued, and conceptualized in the dynamics of teaching and learning in physical education. This perspective is necessary because a common goal for all educational research is to advance the theory of learning and enhance the practice of teaching (Berliner \& Calfee, 1996; Schoenfeld, 1999). A two-level synthetical approach is used in conceptualizing the theories of motivation. At the first level, motivation is conceptualized and understood in the paradigm of educational psychology where research findings are examined in terms of the theoretical tradition of each study. In this way, relevance of the findings to student learning can be assessed. At the second level, motivation is conceptualized and understood as a process characterized by a learner-content interaction in a broad learning context defined by curricular and socioeconomic environments within and beyond the school. It is at this level that the relationship between motivation research and physical education curriculum and learning is scrutinized and interpreted.

\section{Motivation Sources}

Students' needs, cognition, and emotions have been identified as primary motivation sources that initiate and modify learning behavior (Reeve, 1996). Maslow's (1954) need hierarchy illustrates how both physiological and psychological needs can motivate people to engage in different behaviors. In education, 
the motivation effect of needs has been summarized in the theory of self-determination. Deci and Ryan (1985) postulate that an ultimate need for students is the ability to determine and regulate actions based on their own choices rather than extrinsic rewards or pressure. In other words, recognizing the need can motivate learners to regulate their learning behavior to ultimately pursue academic excellence.

In the recent decade, research on self-efficacy and achievement goals has provided strong empirical evidence suggesting that cognition is another source of motivation to learn in school. Defined as "beliefs in one's capability to organize and execute the courses of action required to manage prospective situations" (Bandura, 1997, p. 2), self-efficacy is considered central to students' thoughts about their ability to successfully complete a specific learning task. While self-efficacy research has focused on addressing students' beliefs of their capability to achieve specific performance outcomes, achievement goal theorists attempt to understand students' purpose "behind the particular outcomes individuals strive for" (Dweck, 1992, p. 165).

Goals are cognitive in nature because they are products of thinking (Maehr, 1984). Researchers from the achievement goal perspective are concerned with reasons for motivated behavior. Two primary reasons or goals have been identified in student motivated behaviors. One is to demonstrate superior ability relative to peers, an ego-centered achievement goal. The other is to develop competence or gain mastery of a task, a task-centered achievement goal (Dweck \& Leggett, 1988; Nicholls, 1984). Research on achievement goals has yielded a vast number of findings across many disciplines. A major finding is that students' perceptions of goals are highly related to their conception of ability, in either a dichotomous association (effort and ability are inversely related) or a unified one (effort leads to ability). However, interpretation of this relationship has been very different. Dweck and Leggett (1988) proposed that students' different conceptions of abilities influence the goal they adopt in a task, while Nicholls (1990) argued that different goal orientations (task vs. ego) determine the differentiation in conception of ability.

In addition to needs and cognition, a person's innate, genuine, and spontaneous emotions about a task are considered as another source of motivation. In this category, curiosity and interest are the two most salient components. Curiosity is defined as an emotion derived from individuals' recognition of discrepancy between their knowledge and reality (Berlyne, 1966). In other words, an individual tends to become curious about an activity in an information-deficient environment. Curiosity is very much likely to drive the individual to engage in an activity to satisfy "feelings of mystery, of strangeness, and of wonder" (McDougall, 1923, p. 60). Curiosity produces fear and uncertainty as well as enjoyment (Hidi \& Anderson, 1992).

Interest is defined in general as an emotion derived from a positive personactivity relationship established on a match of unique characteristics between the person and the activity (Krapp, Hidi, \& Renninger, 1992). It can result from either information-deficient or information-surplus environments (Krapp et al., 1992). Unlike curiosity, which brings about feelings of uncertainty, experience of interest is pleasurable in and of itself (Hidi \& Anderson, 1992). Empirical evidence has suggested that high interest is associated with enjoyment (Chen, Darst, \& Pangrazi, 1999; Reeve, 1989); curiosity may not be (Spielberger \& Starr, 1994).

Currently, the achievement goal theories are the dominant theoretical framework that guides most research studies on motivation. As Urdan (1997) summarized, 
student goal orientations and classroom goal-involvement climate are found as the two fundamental factors that account for motivated learning behaviors. It has been reported that the task goal orientation and mastery goal-involvement climate have a positive motivational effect on student learning behavior. Recently, the theory of interest motivation (Hoffmann, Krapp, Renninger, \& Baumert, 1998) has become another viable theoretical platform guiding a number of investigations on contentspecific motivation, especially in reading, science, and mathematics learning. Research on interest has generated significant findings that directly link student emotional responses to the content with their achievement motivation and academic achievement.

The two lines of research are loosely associated through a focus on the importance of learning tasks. Research on achievement goals has shown that a taskfocused goal has positive impact on student motivation in general. Research on interest has provided convincing evidence that student motivated learning behavior and achievement in a specific content area are associated with the extent of situational interest of specific learning tasks. The following sections of this paper are focused on these two lines of research as related to physical education. The intention is to examine and make sense of the findings in terms of what we have learned from the research, how significant the findings are to curriculum design and instruction in physical education, and what we need to know about motivation in the future.

\section{Research on Achievement Goals}

\section{Goal Orientations}

In the recent decade, educational psychologists have demonstrated the value of achievement goal theories in interpreting students' motivated learning behavior. Goals, derived from models of needs in the behavioral perspective (Maslow, 1954; Murray, 1938), can be defined in the social-cognitive perspective as something external to an individual that he or she is consciously trying to attain (Locke \& Latham, 1990). In other words, from this perspective, goals are conceptualized as what to achieve. This family of goal theories includes goal setting theory (see Locke \& Latham, 1990), the motivational systems theory (see Ford, 1992 for a summary), and the goal orientation theory (see Urdan, 1997).

Recently, the goal orientation theory has become one of the most popular motivation theories in education. From this perspective, goals are redefined as why students want to achieve what they achieve (Urdan, 1997). The new definition interprets the purposes that drive student motivated learning behavior in academic achievement settings.

The goal orientation perspective has adopted a dichotomous framework to describe goal-oriented psychological dispositions: mastery (task) goals and performance (ego) goals. Studies on these two goals have been conducted at both individual psychological disposition level (see Nicholls, 1984) and classroom instructional structure level (see Ames, 1992). Vast empirical evidence on goal orientations has shown that the two goals are associated with cognitive, affective, and behavioral outcomes of learning. Briefly, at the individual psychological disposition level, the research has shown that a task-oriented goal allows students to become concerned primarily with the completion of an activity and mastery of the knowledge 
and skill involved. An ego-oriented goal promotes a focus on comparing their own abilities with others' in reference to the activity. When encountering an activity, students who have a task-goal orientation are more likely to concentrate on completing the task, while those who are ego-oriented tend to demonstrate superior ability over that of fellow students.

At the instruction level, researchers (e.g., Ames, 1984) have found that different instructional structures (e.g., cooperative groups, individualistic or competitive structures) may be perceived by students as having different purposes of achievement (goals). These goals, identified as either task-involving or ego-involving, provide a unique motivation climate to the classroom that consequently influences how students interpret success and failure. It has been also documented that a mastery (task) goal oriented instructional structure leads to greater cognitive engagement, better performance, and higher level of affective response to learning (e.g., satisfaction) than a performance (ego) goal oriented instructional structure (Ames, 1992).

Most motivation research in the human movement domain has been conducted in sports and exercise contexts. This research heavily relies on the achievement goal theoretical framework, particularly the underpinnings of goal orientations (Roberts, Treasure, \& Kavussanu, 1997). This framework has been used in most motivation research in physical education settings as well. Adopting this framework assumes that students possess social-cognition-based motivational thought in physical education across elementary and secondary school years. It is also assumed that children's motivation to learn in physical education presumably is determined by their self-perceptions of ability, their goal orientations, and the match of goal orientations with instructional motivation climate (Papioannou, 1995, 1998; Treasure, 1997; Treasure \& Roberts, 1994; Vlachopoulos \& Biddle, 1997; Walling \& Duda, 1995; Xiang \& Lee, 1998).

In physical education, the research has focused on goal orientations as student psychological dispositions. Researchers found that students in upper elementary grades (Spray \& Biddle, 1997; Xiang \& Lee, 1998), secondary schools (Walling \& Duda, 1995), and beyond (Spray, Biddle, \& Fox, 1999) can be identified as task- and ego-oriented. Several other studies listed in Table 1 also support this observation. Students with a high task-oriented goal perceive success and failure in learning as associated with effort, report a high likelihood to select learning tasks with high level of difficulty, and enjoy learning experiences more frequently. In contrast, students with a high ego-orientation tend to avoid difficult learning tasks and attribute success or failure to genetic ability. They are more likely to be motivated when their performance is superior to that of others than when their performance is inferior to their peers.

Student goal orientations are reported to be associated with self-perceptions of physical ability. Goudas, Biddle, and Fox (1994) found that perceived competence in 7 th and 8 th grade students had a mediating effect on their overall goal orientations. The path models the researchers developed showed that high-perceived competence was associated with ego-goal orientation in learning soccer, while the association was not observed in learning gymnastics. The findings indicate that the relationship between students' achievement goal orientations and perceived competence are task-specific and based on self-perceptions of task-specific ability. This association was also observed in other studies (e.g., Vlachopoulos \& Biddle, 1997). Xiang and Lee (1998), however, argue that the association is incon- 


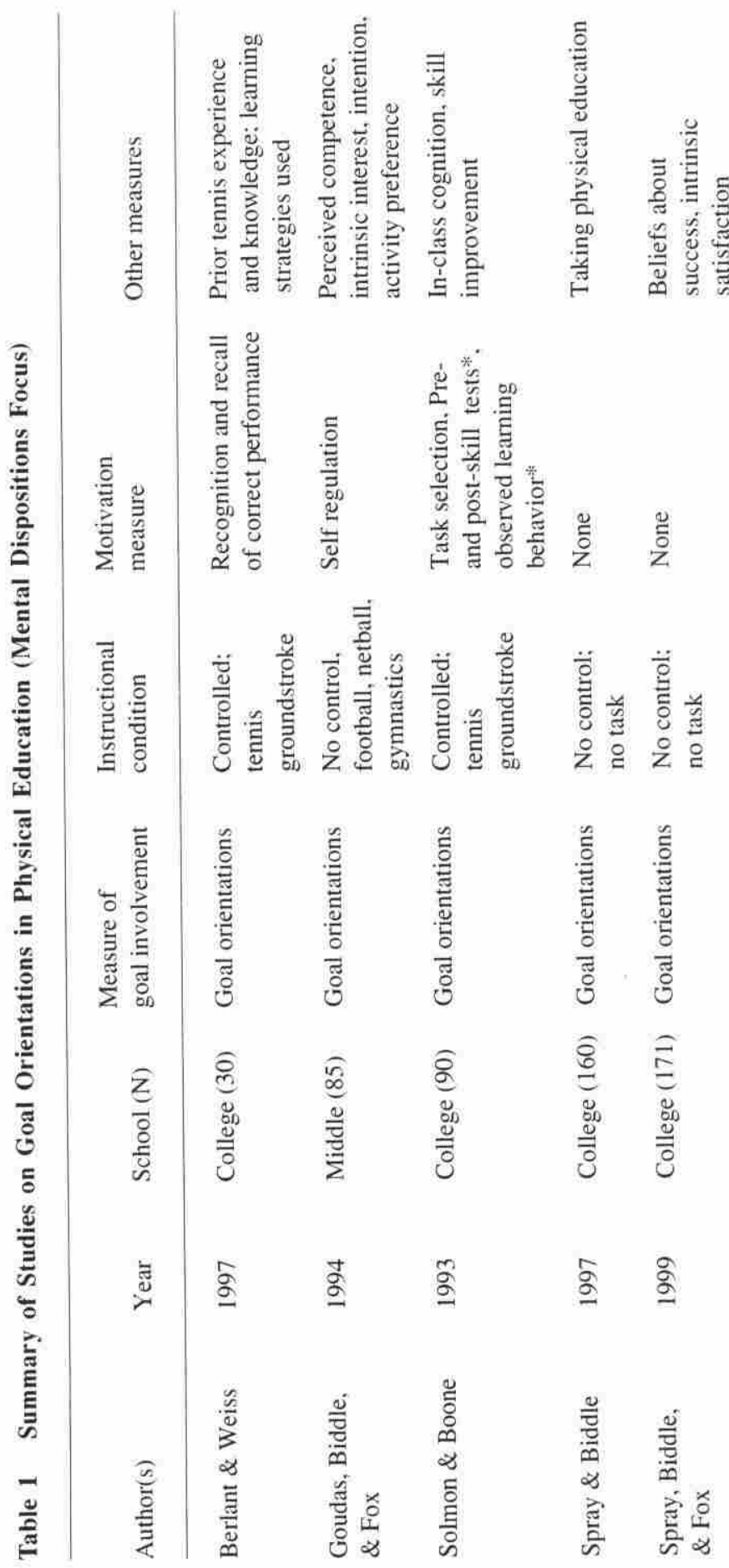




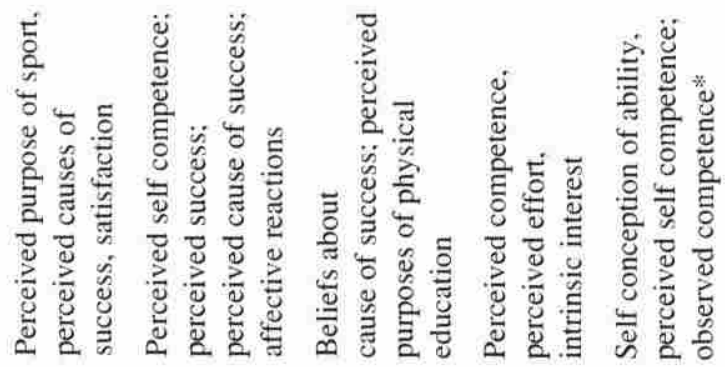

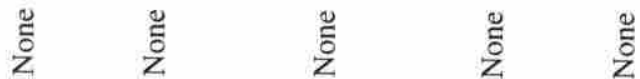

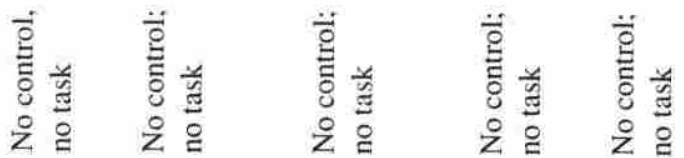

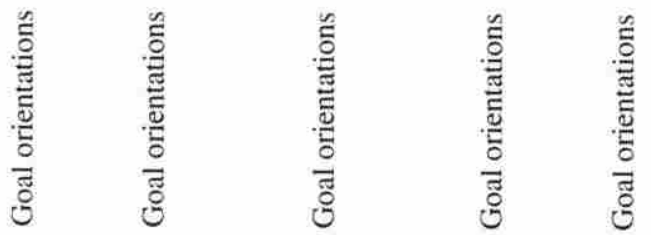

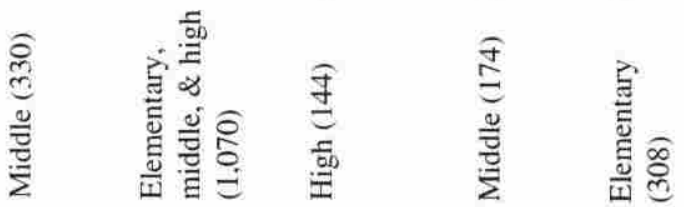

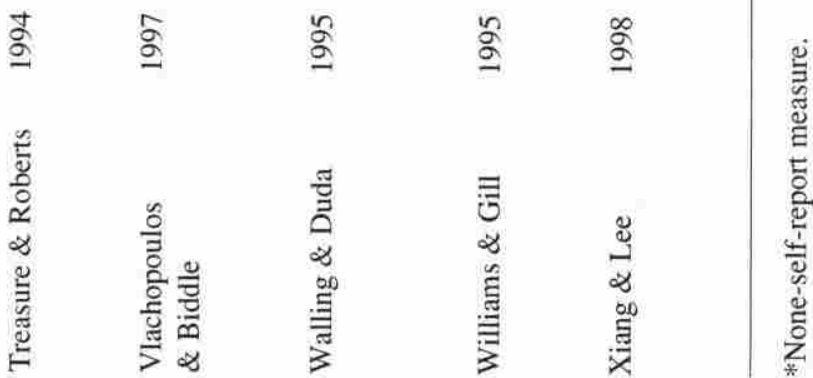


sistent. They reported low or nonassociations between perceived competence and goal orientations in a sample of 4 th, 8 th, and 11 th grade students.

Nevertheless, these findings in general support the assumption that students' goal orientations are functional (Dweck \& Leggett, 1988) in physical education. However, it has been constantly argued (Urdan, 1997) that students' achievement motivation in a given classroom is adaptive to the motivational climate constructed by the instructor and peer students and is specific to the content. Table 2 lists several studies that have been conducted to address this issue in physical education. The findings have indicated that a mastery learning (task involvement) environment is superior to that of performance (ego involvement) in terms of motivating learners. Students in a mastery environment tend to choose difficult tasks to practice (Solmon, 1996), report high intrinsic motivation (Goudas, Biddle, Fox, \& Underwood, 1995; Mitchell, 1996; Papaioannou, 1995), and are likely to indicate a high level of satisfaction in learning (Treasure, 1997). These findings suggest that student motivation is context-and task-dependent and that motivation to learn is dependent upon a task-oriented social environment (Mitchell, 1996; Papaioannou, 1998: Solmon, 1996; Xiang \& Lee, 1998). Particularly, they have revealed a greater motivation potential of a task-oriented approach to teaching and learning in physical education.

\section{Tenability of Goal Orientation as a Motivation Source in Physical Education}

Despite these findings, tenability of using goal orientation theory to interpret motivated learning in physical education seems to be subject to the issues at both theoretical and empirical levels. Urdan and Maehr (1995) raised questions about the theoretical integrity of the two-goal structure of the goal orientation theory. They argue that there is a good possibility that students are motivated to achieve academically for social purposes as well. Defined as "the perceived [social] purposes for trying, or not trying, to achieve academically" (Urdan \& Maehr, 1995, p. 214 , brackets added), social goals are documented as a set of powerful goals that motivate students in academic achievement settings. Although a number of researchers conceptualize adult approval goals as ego goals (e.g., Nicholls, 1984), others (e.g., Maehr, 1984) argue that gaining adult or peer approval is a goal indicative of inter-personal commitment rather than demonstrative of ability.

In classroom research, Wentzel (1989) and others (Juvonen \& Murdock, 1993) have demonstrated that students are likely to pursue a variety of social goals in an academic setting. In physical education, being able to realize a social agenda has been documented as an important purpose for students in a dance class (Hastie \& Pickwell, 1996). For male students, this goal paralleled and even overrode the academic goal of "giving the teacher what she wanted" (p. 179). It seems that the students chose not to try to achieve academically for social purposes. Given that what to achieve academically often is not clearly specified in most physical education programs (Goodlad, 1984; Siedentop, Doutis, Tsangaridou, Ward, \& Rauschenbach, 1994), social goals might be a salient motivation source for students to engage in learning activities.

Pedagogical significance of the findings from physical education seems rather limited because the achievement settings were vaguely defined in most of the studies and instructional variables and learning outcomes were rarely measured. The first 


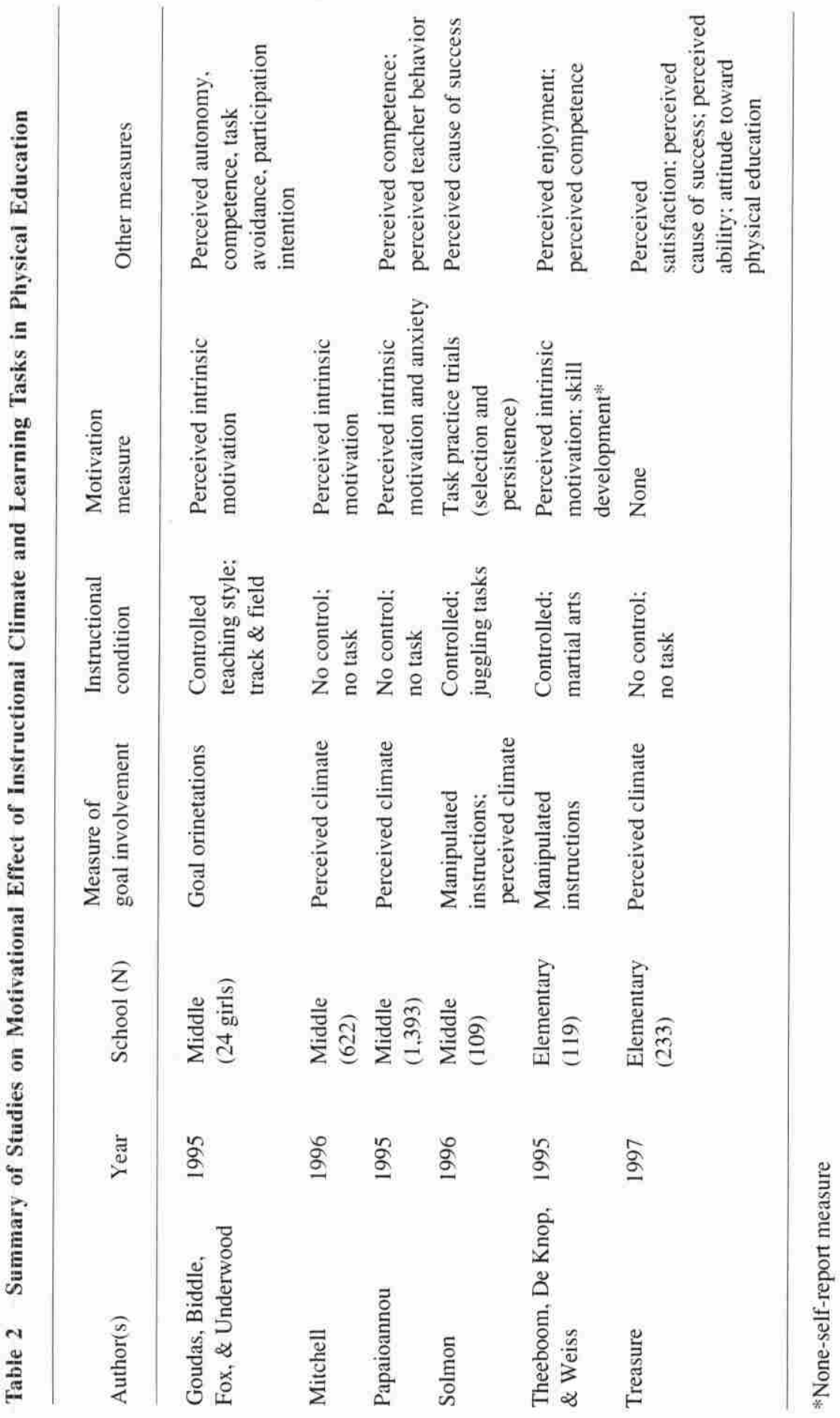


limitation lies in the infrequent attempts to link goal orientation/involvement with learning. The goal orientation theory was developed to explain achievement behavior with various learning tasks. It is based on and geared toward academic achievement situations in which students are expected to achieve various academic goals in different subject content areas. The tenability of the theory has been observed in many classroom studies where student goal orientations were studied in association with learning behavior on specific tasks and academic achievement (Pintrich \& Shunk, 1996). Specified class assignments and/or homework were used as reference stimuli to define the achievement setting in a subject area. However, these reference stimuli were rarely measured or totally absent in most of the studies in physical education.

The second limitation arises from the fact that most of the studies approached the motivation issue only from the perspective of individual psychological dispositions. Contextual variables, such as instructional environment, were measured mostly through students' perceptions rather than through observable contextual indicators such as types and organizations of learning tasks, student involvement levels in decision making, teacher evaluation approaches, reward systems, instructional styles, and classroom discipline policies. The validity of these perception data is subject to students' beliefs that are brought into a learning setting. Stipek (1996) has warned that we might gain little knowledge about the issue of motivated learning if our understanding of motivation environment is based exclusively on students' perceptions.

Several researchers (Berlant \& Weiss, 1997; Solmon, 1996; Theeboom, De Knop, \& Weiss, 1995) investigated students' goal orientations and motivation in studies involving actual manipulation of teaching/learning environments and measures of instructional variables. In Berlant and Weiss' study (1997), college students' attention to tennis forehand ground stroke demonstration was found not related to either task- or ego-orientations. The researchers raised questions about the impact of students' achievement goal orientations on their actual learning behavior. They particularly questioned the appropriateness of exclusively using the achievement goal theory to interpret motivated learning behavior and motivation in motor skill learning settings.

To examine differentiated effects of learning climates on intrinsic motivation, Theeboom et al. (1995) randomly assigned students to either a task/mastery or an ego/performance instruction group to learn martial arts for three weeks in a recreational learning setting. A pre- and post-comparison of variables showed that children in the mastery learning setting reported a higher enjoyment level and better skill performance judged by independent skill raters. A closer examination of motivation sources indicated that curiosity motivation contributed to the enjoyment. No difference was found in children's perceived competence of martial arts between the two instructional groups. It seems that the three-week long instruction, no matter whether mastery/learning based or ego/performance based, had little influence on the children's perceived task-specific competence. In addition, the quantitative data did not show that mastery instructional method enhanced children's intrinsic motivation. Students in both groups demonstrated an equal improvement in all motivation dimensions (challenge, mastery, and curiosity motivations). The findings seem to imply that students' motivation to learn a specific content can be improved in either instructional motivation climate. 
Two additional studies (Solmon, 1996; Solmon \& Boone, 1993) examined the effects of student achievement goal orientations on their learning behaviors. In the first study (Solmon \& Boone, 1993), college students with ego or task orientations were measured on skill achievement (pre- and post-tests of tennis ground stroke), in-class participation behavior (systematic observation by trained observers), task selection (student-teacher contract on learning tasks), and thought processes (Cognitive Process Questionnaire). Canonical correlation analyses showed that task-orientation positively corresponds with learning task selection and thought processes, while ego-orientation is negatively associated with these measures. However, student learning behavior measured through actual observation was not associated with either achievement goal orientations. In addition, students with different orientations showed similar significant improvement in their ground stroke skills over the course of instruction. Through regression analyses, the researchers found that student achievement goal orientations did not predict skill achievement, whereas thought processes and task selection were significant predictors. These findings may suggest that the impact of goal orientations on learning is indirect.

To examine the effect of motivation climate on skill achievement, Solmon (1996) randomly assigned students into either a task/mastery or an ego/performance environment to learn juggling. The task-involving climate was manipulated to emphasize challenge, short-term goals, improvement, and self-referenced criteria, whereas the ego-involving environment promoted winning contests, moving up a competition ladder, and demonstrating superior performance. Student thought processes (cause of success measured by a questionnaire) and learning behavior (persistence in learning measured by trials per minute in easy or difficult tasks) were dependent measures. Results showed that students in the task-oriented learning environment engaged in difficult task trials more often than those in the egooriented environment, while no differences were found in easy task trials. Students in the ego-oriented environment were more likely to attribute success to ability than were those in the task-oriented environment. The regression analysis revealed that the actual motivation climates measured by observation coding method were valid predictors for the differentiation in the number of trials in difficult tasks. Students' perceived climates, however, did not appear to be a valid predictor. Solmon (1996) concluded that situational influences are powerful factors that account for major variations in motivated learning.

These studies indicate that student achievement goal orientations might have an indirect and weak influence on student learning behavior. Consistently, the findings suggest a rather strong association between situational factors, especially characteristics of learning tasks, and student learning behavior. It may be summarized that in physical education, student motivation to learn is more likely to depend on specific learning tasks than it is on achievement goal orientations.

\section{Research on Interest}

\section{Interest in Motivation Research}

In the paradigm of motivational research, interest and its motivational function have recently regained attention of researchers. According to Krapp et al. 
(1992), interest has been conceptualized as personal interest and situational interest. Personal interest is a person's psychological disposition in preference of an activity or an action. It is often regarded as a personal preference stemming from conceptualization of knowledge, beliefs, and values. Personal interest is considered to have developed slowly over time during constant and consistent interaction with certain activities in a particular environment.

Situational interest is defined as the appealing effect of characteristics of an activity on individuals (Hidi \& Anderson, 1992). It depends on a person-activity interaction in which the person is able to recognize the appealing characteristics of the activity (Mitchell, 1993). Educational researchers (Renninger, Hidi, \& Krapp, 1992) consider that situational interest possesses stronger potential than personal interest for educators to use in designing the curriculum and classroom strategies that motivate students to learn.

\section{Motivational Function of Interest}

In general, achievement motivation as a research construct can be measured through indices of task choice, effort, persistence, and achievement (Pintrich \& Schunk, 1996). Motivated individuals often choose to engage in tasks for a longer time than less motivated ones do. They are willing to put more effort, both physical and cognitive, into a task. Motivated individuals demonstrate strong persistence in the task, especially when encountering difficulties. Although achievement is not a direct measure of motivation, it is a reliable indicator of motivation. It has been documented in numerous studies that students who choose to engage, expend effort, and persist in tasks are likely to achieve at a higher level (Pintrich \& Schunk, 1996).

Both personal and situational interests have high level motivational functions. The measurement indices are often manifested when a person is becoming interested in an activity. It can be commonly observed in daily life and has been widely documented in research that individuals will choose to engage, put forth effort, and persist in an activity that personally interests them (Renninger et al., 1992).

High interest is associated with academic achievement. Based on a comprehensive meta-analysis, Schiefele, Krapp, and Winteler (1992) have reported that personal interest has a significant average correlation of above .30 with achievement across all major content areas. When using knowledge representation as a measure of reading achievement, researchers (Hidi, 1990; Schiefele et al., 1992; Hidi \& Anderson, 1992) found stronger effects of personal interest on learning achievement, showing that becoming interested leads students to a high level engagement required for a high level achievement. Csikszentmihalyi (1990) has identified it as a "flow" state when an individual has merged with an activity of personal interest. In this state, the person is completely motivated by his/her personal interest and becomes inseparable from the activity. This personal interest driven motivation can be seen when a scientist is engaged in an experiment, a dancer or an athlete in a performance, and a student in a meaningful assignment.

Personal interest is considered as evolving along with a person's knowledge repertoire and value system (Krapp et. al., 1992). It is rooted in personal beliefs determined by knowledge and values about an activity. Thus, it is very stable and difficult to change within a person. Yet, because individuals vary in their knowledge and values, there are tremendous individual differences in personal interests. It is difficult for teachers to decide how much effort they should invest in using student 
personal interests to facilitate learning in a particular subject. To a certain extent, making such a decision itself is impossible when the teacher has little knowledge of how well students' personal interests match the content they are learning (Hidi \& Anderson, 1992).

The effects of situational interest on academic achievement were studied primarily in the content areas of reading and science education. Most research has been focused on the role of certain text characteristics in text-based learning (e.g., Frick, 1992; Hidi, 1990; Hidi \& Baired, 1986; Tobias, 1995). In general, researchers found interesting texts motivate the learner to read, enhance their comprehension, and result in a higher level of achievement measured both quantitatively and qualitatively. However, the effects of situational interest on learning achievement are mediated by the importance of information conveyed in the text. Garner, Gillingham, and White (1989) demonstrated that interesting but unimportant information in the text (seductive details) might interfere with and jeopardize the learning of important information.

The relationship between situational interest and attention, effort, and persistence remains vague. Csikszentmihalyi (1988) and Garner et al. (1989) speculate that when an interesting task is encountered, the learner would attend to the task longer, put forth more effort, and demonstrate stronger persistence at the task. Others (Hidi, 1990; Hidi \& Anderson, 1992) argued that individuals tend to spend their energy more efficiently and economically. Interesting tasks lead to a spontaneous but shorter and more intense attention span, intensive but less amount of effort, and necessary persistence for completing the task successfully. Clearly, more research is needed to clarify whether situational interest may involve more prolonged and/or less effortful learning.

\section{Interest Research in Physical Education}

Research on interest in physical education has been scarce. In some studies, interest was conceptualized as equivalent to preference or liking of the content. Lumpkin and Avery (1986) surveyed university students to determine whether they were interested in specific activity course offerings. They found that college students were predominantly interested in taking individual sport lessons. No team sports were among the top 10 choices.

Van Wersch, Trew, and Turner (1992) investigated age and gender differences in interest in physical education among middle and high school students. They found a gender and age interactive effect on students' interest. At a younger age, girls demonstrated higher interest in physical education than boys, while at an older age, boys' interest became stronger than that of girls. For both boys and girls, interest in physical education declined with the increase of age. The researchers attributed the decline to students realizing that physical education was not as important as other subject matter. The data in Goodlad's (1984) national study also showed that students considered physical education to be least important, although they liked it more than other academic content. These studies have provided useful data on student preference (or nonpreference) for the content of physical education. The findings, however, have little significance in helping us understand how interest, as a motivator, influences learning in physical education.

Adopting the theoretical framework of interest, Chen and his colleagues recently examined interest in student learning in physical education with manipulation of several learning variables such as achievement level, activity interest level, and 
cognitive/physical demand of learning tasks (Chen, 1996; Chen \& Darst, in press; Chen, Darst, \& Pangrazi, 1999). Chen (1996) asked a group of physically active college students to reflect on situational interest in physical activities in their secondary school curriculum. The students sorted 60 physical activities on a Q-scale in terms of situational interest of the activities and provided rationales for their sorting decisions. Results showed that the extent of perceiving situational interest of the physical activities depended on a diverse personal interpretation of meaning in the activities and learning tasks. It was the match of situational interest in an activity and personal interpretation of meaning that motivated the students to pursue continued participation in the activities.

Situational interest has been articulated theoretically (Deci, 1992) as a multisource construct that can be reported by an individual when an activity provides a sense of novelty and challenge, demands exploratory action and high level attention, and generates a feeling of instant enjoyment. Chen et al. (in press) tested the tenability of this theoretical model with physical education learning tasks. The findings indicate that those physical activities that provide new information, demand high level attention, encourage exploration, generate instant enjoyment, but present low physical challenge are situationally interesting to middle school students.

In the literature, situational interest is assumed to be a function of learning task design (Renninger et al., 1992). Different learning tasks may have different levels of motivational appeal to students. Teachers should consider the aspect of information and the aspect of motivation in designing learning tasks in order for students to be motivated when encountering the tasks. Unfortunately, as Burke (1995) observed, the interactive effects of the two aspects rarely have been examined. Therefore, we have little information about how to design learning tasks that are interesting and motivating. In physical education, learning tasks are designed usually on several platforms such as the skill (e.g., open vs. closed skills), class management (e.g., time on task), or function of the activity (e.g., health-related fitness or skill acquisition).

Cognitive and physical demands are two fundamental manipulative components that can be used in learning task design in physical education (Schmidt \& Lee, 1998). The interplay of the two components determines the acquisition of cognitive knowledge and physical skills. Chen and Darst (in press) examined the effects of different cognitive and physical demands of learning tasks on situational interest. Middle school students evaluated situational interest of four learning tasks representing various combinations of cognitive and physical involvement when participating in the learning process. The results showed that cognitive demand in a physical activity determines the level of situational interest. The students considered the tasks with high cognitive demand, regardless of physical demands, highly interesting. Tasks with low cognitive and physical demand were evaluated particularly low in situational interest. From these studies, we come to know that students might consider those learning tasks interesting that are novel, cognitively engaging, demand exploration and high level attention, and generate instant enjoyment.

Although the inquiry in interest has provided informative data about sources of interest and motivation and importance of task design, it has not established the link between high situational interest and learning achievement. In these studies, despite the fact that student responses were based on experiences in learning tasks, 
the measurement settings cannot be considered an achievement setting. Thus, it is difficult for researchers and teachers to conclude that learning achievement can be accounted for by high situational interest of learning tasks.

\section{Revisiting Motivation Issues in Physical Education}

There are several important implications of the motivation research to curriculum designers and teachers in physical education. First of all, we know that students come to our classes with different achievement goal orientations that are, primarily, task-, ego-, or perhaps social-focused (Urdan \& Maehr, 1995). Second, we know that task-goal-oriented students are more likely than those with ego-goal orientation to report selecting challenging tasks, exerting effort in learning, and attributing success to their effort instead of ability. Third, we know that situational influences may have a stronger impact on students' motivation to learn than their goal orientations. Fourth, it seems to be consistent in the findings that how learning tasks are designed is a crucial situational factor that directly affects students' motivation. Therefore, what can physical education teachers do to motivate students to learn? To answer this question, however, requires us to reconceptualize issues of student motivation in physical education.

Evidently, students' low motivation is not a problem only in physical education. Numerous studies have documented that motivation is an age-related, developmentally progressive phenomenon. It is not unusual to find that students "either don't have it, have too much of it, or invest it in the wrong activities" (Anderman \& Màehr, 1994, p. 287).

It seems that the severity of motivation issues in physical education varies in terms of the content offered and the opportunity for students to select the content. In a multi-year study on schooling, the U.S. Department of Education documented enrollment changes in courses taken by high school students during a 12-year period (National Center for Education Statistics [NCES], 1998). Approximately 25,000 students' transcripts from each of the school years of 1982, 1987, 1990, and 1994 were sampled and compared. Consistent with the data in the Surgeon General's report on physical activity and health (U.S. Department of Health and Human Services, 1996), enrollment in physical education decreased dramatically during this period, although the total enrollment in high schools increased. A close examination of the entire data set revealed, however, that the decrease occurred during 10 th, 11 th, and 12 th grades. The data showed that enrollment in general physical education (programmed in a package of multiple sports and physical activities) dropped from $60.51 \%, 37.37 \%$ and $29.17 \%$ for 10 th, 11 th, and 12 th grade students in 1982 to $34.55 \%, 16.45 \%$, and $8.58 \%$ in 1994 , respectively. It may be inferred from these data that most students decide not to take general physical education after they have fulfilled their graduation requirements.

While enrollment in general physical education dropped, enrollment remained about the same for individual sport courses $(5.44 \%$ in 1982 to $5.70 \%$ in 1994) and increased for team sport courses $(9.51 \%$ in 1982 to $14.72 \%$ in 1994). Enrollment in fitness/conditioning increased from $5.54 \%$ to $14.55 \%$. Although little inference can be drawn from the data to show students motivation changes, the data do show that the students prefer activity-specific courses rather than general physical education courses. In other words, they are more likely to take those courses that are consistent with their personal interest. 
The increase in enrollment in specific physical activities can also be observed in the data documenting school-sponsored after-school sport and recreation programs. In 1988, a total of $33.6 \%$ high school seniors reported taking afterschool sport lessons or participating in varsity athletics and recreational physical activity clubs during their high school years (NCES, 1996). In 1992, 42.90\% seniors reported participating in these programs. National data (NCES, 1995) show that $98.70 \%$ secondary schools in the country offer after-school competitive and recreational sport programs for students. Given that most high schools are required to offer physical education to fulfill the graduation requirement, and almost all schools offer after school sport programs, it seems that the opportunity for students to participate in physical activity is adequate and sufficient in schools. It is also encouraging to notice that about $43 \%$ of high school students have taken the opportunity to participate in those activities.

If we consider students' choice as an important indicator of their motivation (Printich \& Schunk, 1996), the above data have sent a mixed message. The decrease in enrollment in general physical education courses appears to suggest a decrease in motivation. The increase of enrollment in sport-specific and fitness courses and after-school programs indicates otherwise. The data appear to suggest that students' motivation in physical education is content specific. It can be assumed that students are motivated when they have the opportunity to choose specific courses to take and activities in which to participate. The question whether students are motivated to learn in the courses that they have chosen remains unanswered. It seems that the motivational effect of the content and learning context should be the center of future inquiry in motivation.

\section{Reframing Motivation Research in Physical Education}

There is no doubt that the research on goal orientations and interest has advanced our knowledge about student motivational dispositions in physical education. Importantly, the findings strongly support the notion that students possess preset purposes or goals upon entering physical education classes (Solmon \& Lee, 1996). They imply that the preconceived goals mediate learning behaviors and outcomes (Lee, 1997). In addition, it has been revealed that the design of learning tasks plays a critical role in manipulating students' motivational perceptions and interest in learning (Chen \& Darst, in press; Solmon, 1996; Theeboom et al, 1995). The findings, derived from individual studies based on different theoretical emphases, indicate a need to reframe motivation research in physical education. As identified recently by both pedagogical researchers (Burke, 1995) and educational psychologists (Anderman \& Maehr, 1994; Urdan, 1997; Urdan \& Maehr, 1995), the link between motivation research and schooling is very weak. This weak linkage has limited the theoretical significance and practical impact of motivation research to the education community.

The linkage should be strengthened in three aspects. They include linking motivation to specific learning settings, to the curriculum/content, and to socioeconomic and cultural environment beyond the school. These links, discussed in the following sections, may serve as a theoretical platform or framework for future motivation research in physical education. 


\section{Linking Motivation to the Learning Setting}

It is apparent that in physical education, motivation research is exclusively based on the same assumption that has guided most classroom research. It is assumed that schools and individual classes provide an unquestionable achievement setting, defined as a learning environment where students are expected to reach academic excellence by increasing academic competence, mastering new knowledge and skills, and understanding meanings of life (Reeve, 1996). It is also assumed that students understand this setting when they are in school in terms of why they should achieve in different content areas. Logically, the internal and external validity of data from the research on motivation relies on the extent to which the assumption is met in the research setting.

It appears that an achievement setting consistent with the above definition rarely can be observed in physical education (not athletics/sport). In a large-scale investigation of American schools, involving 38 schools in 13 stratified community samples across the country, 8,624 parents, 1,350 teachers, and 17,163 students, Goodlad (1984) found that physical education does not appear to have learning goals for students to achieve. Although physical education is the content that students like the most and are most willing to participate in, the curriculum does not provide a standard of excellence that specifies what students should achieve. Physical education as a content area has failed to develop an achievement learning environment despite students' positive preference for the content. Goodlad observed that most local physical education curricula are unstructured and lack a clear focus for learning achievement. It may be concluded that when students appear to be unmotivated in physical education, they actually are confused and disoriented in this nonachieving curriculum and learning setting.

Researchers in physical education have documented many cases of student disengagement in classes (Graham, 1995), especially in urban settings (see Ennis, 1995, 1996; Ennis, Cothran, \& Davidson, 1997). Siedentop and colleagues (1994) reported that in most physical education classes, showing up, punctuality, dress out, and overall deportment are the content. In such a learning environment, there is little content-related achievement. Students typically do not know what to study or practice when they come to physical education classes (Siedentop et al., 1994). Consequently, they might know little about what to achieve. It appears logical to reason that this nonachieving setting may limit the significance of using goal orientation theory to interpret and promote students' motivation in physical education.

As opposed to those goal-less and nonachieving settings, several physical education curriculum models (Jewett, Bain, \& Ennis, 1995) do exist in schools. These models emphasize different learning achievement goals and create various achievement settings. Studying student motivation in these settings may provide insightful information about the nature of student motivation in physical education and about how student motivation varies according to the differentiation of achievement settings created by these curriculum models.

\section{Linking Motivation to the Curriculum}

Lack of achievement settings may lead to a problematic conceptualization of motivation issues in physical education. From the above review of research in 
physical education, one can find that motivation issues are conceptualized mainly as either students' personal psychological disposition of achievement goals or interest or their perceived adaptation to learning tasks, teaching methods, and rewarding systems for achievement. This conceptualization tends to overlook the role that the curriculum plays in motivation. Burke (1995) noticed that among the six components that define learning outcomes (persons, places, time, content, methods, and materials), pedagogy researchers and psychologists tend to focus on different components separately. The connection between the study of the person (motivation) and the study of the content (pedagogy) has been missing for too long in educational research.

To link motivation to content is crucial for educators to fully understand issues associated with achievement motivation in school settings and to design curricula that motivates the learner. Educational psychologists (Anderman \& Maehr, 1994) postulated that motivation is caused by cognition. In an academic achievement setting such as school, learner cognition is surrounded, nurtured, and developed by a context centered on the content. For a content to be motivating, as Anderman (1997) argued, the learning tasks should be personally meaningful to the learner. A learner who has never seen a train can find it uninteresting and demotivating to learn algebra concepts by solving problems involving calculating the time that two trains take to travel at different speed (Anderman, 1997). These observations are consistent with the constructivist curriculum design theory that centers on learners' active construction of knowledge and skills.

Educational psychologists and curriculum researchers seem to agree that a motivating curriculum and its learning tasks should be personally meaningful to the learner (Anderman, 1997; Anderman \& Maehr, 1994; Newmann, Marks, \& Gamoran, 1996). Personal meaningfulness, however, does not always lead to educational achievement in the learner. Meaning could be made out of shallow and artificial information that contributes little to acquisition of in-depth knowledge and skill (Newmann et al., 1996). This type of meaning will have little impact on the future of the learner. Newmann et al. (1996) argued that an educationally meaningful curriculum should provide students with authentic learning experiences and tasks. The authenticity is embedded in the characteristics of the content that call upon students' genuine effort to construct new knowledge and skill, initiate disciplined inquiry, and value learning beyond the school (Newmann et al., 1996). Although such a curriculum is not commonplace in school physical education, the possibility has been articulated recently by curriculum theorists in the field (Kirk, 1997).

In schools, the curriculum with which students interact on a daily basis is an environmental factor that has powerful influence on student motivation. Newmann et al. (1996) argue that the content forms the context in which students spend most of their daily lives in school and suggest that this context also provides a reference frame for students to define and determine the level of success in education. The curriculum, therefore, can be viewed as what students get energized for as well as what influences the process of the internal energizing. Burke (1995) observed that content that stimulates interest, curiosity, and self-fulfillment serves as an excellent motivator. Given the importance of content, it is assumed that research on student motivation can be meaningful only when student motivation is studied in the context of a specific content and in association with learning achievement (Burke, 1995). 


\section{Linking Motivation to Socioeconomic and Cultural Environment}

As Berliner and Biddle (1995) have pointed out, low motivation/ low achievement is associated with socioeconomically disadvantaged environments. The influence of socioeconomic and cultural variables on achievement motivation has rarely been examined in motivation research in education (Urdan, 1997). Neither has it been examined in physical education.

It has been well documented that students growing up in socioeconomically disadvantaged neighborhoods are more likely than those in affluent communities to hold a negative attitude toward schooling, to care less for academic achievement, and to perceive their competence in a negative way (Berliner \& Biddle, 1995; McQuillan, 1998). In extreme cases, they are motivated to "achieve" failure and create a counter-achieving or demotivating culture to disable their own desire for education and ability to learn (McDermott \& Verenne, 1995).

In physical education, students from socioeconomically disadvantaged environments are likely to disengage from the content and learning tasks (Chen, 1999; Ennis, 1995, 1996). They either show explicitly their disinterest in the content or engage in disruptive activities, investing their motivation in wrong directions (Anderman \& Maehr, 1994). Although fearing failure could be an influential factor, learned helplessness chronologically developed from a disadvantaged home environment certainly contributes to the demonstrated low motivation in some cases (Martinek \& Griffith, 1994). McQuillan (1998) speculates that constantly attributing failure to lack of competence in home and community life forms a negative psychological context for these students to devalue motivated learning and academic achievement.

Linking motivation issues with the socioeconomic environment may provide an opportunity for researchers to examine causality of low motivation from a broader perspective. For instance, the U.S. Department of Education (NCES, 1996) has reported that students' access to the school sponsored after-school physical activities is restricted by socioeconomic conditions of the community that the school serves. On average, schools in economically underdeveloped urban areas offer two activities less in their after-school programs than those offered by schools in affluent suburban areas. Consequently, while $55 \%$ of suburban students choose to participate in school sponsored after-school sports programs, less than $40 \%$ of students in urban schools are able to do so. Reflecting on the impact of social change on physical education, the teacher in Chen's case study (1999) affirmatively attributed her students' unmotivated learning behavior to reduced after-school physical activity opportunities due to violence and other social problems associated with socioeconomic disadvantages in an urban neighborhood. Additional studies are needed to examine how differentiated access to various opportunities of physical activities outside the school affects students' motivation to learn in physical education classes.

\section{Conclusion}

Motivation research in education has advanced beyond the realm of psychology. It is conceptualized in the educational research community as a topic demanding scholarly attentions from psychology, curriculum and instruction, 
educational policy, and educational sociology (Anderman, 1997; Anderman \& Maehr, 1994; Burke, 1995; Urdan, Midgley \& Wood, 1995; Wentzel, 1989). In physical education, we are yet to begin to address the issue in such a broadened spectrum that links student motivation to learn to the environment of schooling. The proposed theoretical integration might be a step toward addressing this issue in physical education research. From this integrated perspective, it is important and necessary to take the multi-link perspective in examining student motivation in a school-based physical education setting. It will significantly enrich curriculum design theories, improve teaching effectiveness, and enhance student learning achievement in physical education.

\section{References}

Ames, C. (1984). Competitive, cooperative, and individualistic goal structures: A cognitive-motivational analysis. In R. Ames \& C. Ames (Eds.), Research on motivation in education (Vol. 1, pp. 177-207). New York: Academic Press.

Ames, C. (1992). Classrooms: Goals, structures, and student motivation. Journal of Educational Psychology. 84, 261-271.

Anderman, E.M. (1997). Motivation and school reform. In M.L. Maehr \& P.R. Pintrich (Eds.), Advances in motivation and achievement (Vol. 10, pp. 303-337). Greenwich, CT: JAI Press.

Anderman, E.M., \& Maehr, M.L. (1994). Motivation and schooling in the middle grades. Review of Educational Research, 64, 287-309.

Bandura, A. (1997). Self-efficacy: The exercise of control. New York: Freeman.

Berlant, A.R., \& Weiss, M.R. (1997). Goal orientation and the modeling process: An individual's focus on form and outcome. Research Quarterly for Exercise and Sport. 68. $317-330$.

Berliner, D.C., \& Biddle, B.J. (1995). The manufactured crisis: Myths, fraud, and the attack on American's public schools. Reading, MA: Addison-Wesley.

Berliner, D.C., \& Calfee, R.C. (1996). In D.C. Berliner \& R. C. Calfee (Eds.), Handbook of Educational Psychology (pp.1020-1022). New York: Macmillan.

Berlyne, D.E. (1966). Curiosity and exploration. Science, 153, 25-33.

Burke, D.J. (1995). Connecting content and motivation: Education's missing link. Peabody Journal of Education, 70, 66-81.

Chen, A. (in press). Situational interest in physical education: A function of learning task design. Research Quarterly for Exercise and Sport.

Chen, A. (1999). The impact of social change on inner-city high school physical education: An analysis of a teacher's experiential account. Journal of Teaching in Physical Education. 18, 312-335.

Chen, A., \& Darst, P.W. (in press). Situational interest in physical education: A function of learning task design. Research Quarterly for Exercise and Sport.

Chen, A., Darst, P.W., \& Pangrazi, R.P. (1999). What constitutes situational interest? Validating a construct in physical education. Measurement in Physical Education and Exercise Science, 3, 157-180.

Csikszentmihalyi, M. (1988). Motivation and creativity: Towards a synthesis of structural and energistic approaches to cognition. New Ideas in Psychology, 6, 159176. 
Csikszentmihalyi, M. (1990). Flow: The psychology of optimal experience. New York: Harper \& Row.

Deci, E.L. (1992). The relation of interest to the motivation of behavior: A self-determination theory perspective. In K.A. Renninger, S. Hidi, \& A. Krapp (Eds.), The role of interest in learning and development (p. 43-69). Hillsdale, NJ: LEA.

Deci, E.L., \& Ryan, R.M. (1985). Intrinsic motivation and self-determination in human behavior. New York: Plenum Press.

Dweck, C.S. (1992). The study of goals in human behavior. Psychological Science, 3, 165-167.

Dweck, C.S., \& Leggett, E.L. (1988). A social-cognitive approach to motivation and personality. Psychological Review, 95, 256-273.

Ennis, C.D. (1995). Teachers' responses to noncompliant students: The realities and consequences of a negotiated curriculum. Teaching and Teacher Education, 11, 445-460.

Ennis, C.D. (1996). When avoiding confrontation leads to avoiding content: Disruptive students' impact on curriculum. Journal of Curriculum and Supervision, 11, 145-162.

Ennis, C.D., Cothran, D.J., \& Davidson, K.S. (1997). Implementing curriculum within a context of fear and disengagement. Journal of Teaching in Physical Education, 17, 52-71.

Ford, M. (1992). Motivating humans: Goals, emotions, and personal agency beliefs. Newbury Park, CA: Sage.

Frick, R.W. (1992). Interestingness. British Journal of Psychology, 83, 113-128.

Garner, R., Gillingham, M.G., \& White, C.S. (1989). Effects of "seductive details" on macroprocessing and microprocessing in adults and children. Cognition and Instruction, 6, 41-57.

Goodlad, J.I. (1984). A place called school: Prospects for the future. New York: McGrawHill.

Goudas, M., Biddle, S.J.H., \& Fox, K.R. (1994). Perceived locus of causality, goal orientations, and perceived competence in school physical education classes. British Journal of Educational Psychology, 64, 453-463.

Goudas, M., Biddle, S.J.H., Fox, K.R., \& Underwood, M. (1995). It ain't what you do, it's the way that you do it! Teaching style affects children's motivation in track and field lessons. The Sport Psychologist, 9, 254-264.

Graham, G. (Ed.). (1995). Physical education through students' eyes and in students' voices [Monograph]. Journal of Teaching in Physical Education, 14.

Hastie, P.A., \& Pickwell, A. (1996). Take your partners: A description of a student social system in a secondary school dance class. Journal of Teaching in Physical Education, 15, 171-187.

Hidi, S. (1990). Interest and its contribution as a mental resource for learning. Review of Educational Research, 60, 549-571.

Hidi, S. \& Baired,W. (1986). Interestingness - A neglected variable in discourse processing. Cognitive Science, 10, 179-194.

Hidi, S., \& Anderson, V. (1992). Situational interest and its impact on reading and expository writing. In K.A. Renninger, S. Hidi, \& A. Krapp (Eds.), The role of interest in learning and development (pp. 215-238). Hillsdale, NJ: LEA.

Hoffmann, L., Krapp, A., Renninger, K.A., \& Baumert, J. (Eds.). (1998). Interest and learning. Kiel, Germany: Institute for Science Education at the University of Kiel.

Jewett, A.E., Bain, L.L., \& Ennis, C.D. (1995). The curriculum process in physical education. Dubuque, IA: Wm. C. Brown. 
Juvonen, J., \& Murdock, T. (1993). How to promote social approval: Effects of audience and achievement outcome on publicly communicated attributions. Journal of Educational Psychology, 85, 365-376.

Kirk, D. (1997). Thinking beyond the square: The challenge to physical educators in new times. Quest, 49, 182-186.

Krapp, A., Hidi, S., \& Renninger, K.A. (1992). Interest, learning, and development. In K.A. Renninger, S. Hidi, \& A. Krapp (Eds.), The role of interest in learning and development (pp. 1-26). Hillsdale, NJ: LEA.

Lee, A.M. (1997). Contributions of research on student thinking in physical education. Journal of Teaching in Physical Education, 16, 262-277.

Locke, E.A., \& Latham, G.P. (1990). A theory of goal setting and task performance. Englewood Cliffs, NJ: Prentice Hall.

Lumpkin, A. \& Avery, M. (1986). Physical education activity program survey. Journal of Teaching in Physical Education, 5, 185-197.

Maehr, M.L. (1984). Meaning and emotion: Toward a theory of personal investment. In R.E. Ames \& C. Ames (Eds.), Research on motivation in education: Vol. 1. Student motivation (pp. 115-144). New York: Academic Press.

Martinek, T.J., \& Griffith, J.B. (1994). Learned helplessness in physical education: A developmental study of causal attributions and task persistence. Journal of Teaching in Physical Education, 13, 108-122.

Maslow, A. (1954). Motivation and personality. New York: Harper.

McDermott, R., \& Verenne, H. (1995). Culture as disability. Anthropology and Education Quarterly, 26, 324-348.

McDougall, W. (1923). Outline of psychology. New York: Scribner.

McQuillan, P.J. (1998). Educational opportunity in an urban American high school: A cultural analysis. Albany, NY: SUNY Press.

Mitchell, M. (1993). Situational interest: Its multifaceted structure in the secondary school mathematics classroom. Journal of Educational Psychology, 85, 424-436.

Mitchell, S.A. (1996). Relationships between perceived learning environment and intrinsic motivation in middle school physical education. Journal of Teaching in Physical Education, 15, 369-383.

Murray, H.A. (1938). Explorations in personality. New York: Oxford University Press.

National Center for Education Statistics. (1995). Educational policy issues: Extracurricular participation and student engagement. Washington, DC: Office of Educational Research and Improvement, U.S. Department of Education.

National Center for Education Statistics. (1996). National Education Longitudinal Study: 1988-1994. Washington, DC: Office of Educational Research and Improvement, U.S Department of Education.

National Center for Education Statistics. (1998). The 1994 high school transcript study. Washington, DC: Office of Educational Research and Improvement, U.S. Department of Education.

Newmann, F.M., Marks, H.M., \& Gamoran, A. (1996). Authentic pedagogy and student performance. American Journal of Education, 104, 280-312.

Nicholls, J.G. (1984). Conceptions of ability and achievement motivation. In R.E. Ames \& C. Ames (Eds.), Research on motivation in education: Vol. 1. Student motivation (pp. 39-73). New York: Academic Press.

Nicholls, J.G. (1990). What is ability and why are we mindful of it? A developmental perspective. In R. Sternberg \& J. Kolligian (Eds.), Competence considered (pp. 11-40). New Haven, CT: Yale University Press. 
Papaioannou, A. (1995). Differential perceptual and motivational patterns when different goals are adopted. Journal of Sport \& Exercise Psychology, 17, 18-34.

Papaioannou. A. (1998). Students' perceptions of the physical education class environment for boys and girls and the perceived motivational climate. Research Quarterly for Exercise and Sport, 69, 267-275.

Pintrich, P.R., \& Schunk, D.H. (1996). Motivation in education: Theory, research and applications. Englewood Cliffs, NJ: Prentice-Hall.

Reeve, J. (1989). The interest-enjoyment distinction in intrinsic motivation. Motivation and Emotion, 13, 83-103.

Reeve, J. (1996). Motivating others: Nurturing inner motivational resources. Needham Heights, MA: Allyn \& Bacon.

Renninger, K.A., Hidi, S., \& Krapp, A. (Eds.) (1992). The role of interest in learning and development. Hillsdale, NJ: LEA.

Roberts, G.C., Treasure, D.C., \& Kavussanu, M. (1997). Motivation in physical activity context: An achievement goal perspective. In M.L. Maehr \& P.R. Pintrich (Eds.), Advances in motivation and achievement (Vol. 10), 413-447.

Schiefele, U., Krapp, A., \& Winteler, A. (1992). Interest as a predictor of academic achievement: A meta-analysis of research. In K.A. Renninger, S. Hidi, \& A. Krapp (Eds.), The role of interest in learning and development (pp. 183-212). Hillsdale, NJ: LEA.

Schmidt, R.A., \& T. Lee (1998). Motor control and learning: A behavioral emphasis (3rd ed.). Champaign, IL: Human Kinetics.

Schoenfeld, A.H. (1999). Looking toward the 21 st century: Challenges of educational theory and practice. Educational Researcher, 28(7), 4-14.

Siedentop, D., Doutis, P., Tsangaridou, N., Ward, P., \& Rauschenbach, J. (1994). Don't sweat gym! An analysis of curriculum and instruction. Journal of Teaching in Physical Education, 13, 375-394.

Solmon, M.A. (1996). Impact of motivational climate on students' behaviors and perceptions in a physical education setting. Journal of Educational Psychology, 88, 731-738.

Solmon, M.A. \& Boone, J. (1993). The impact of student goal orientation in physical education classes. Research Quarterly for Exercise and Sport, 64, 418-424.

Solmon, M.A., \& Lee, A.M. (1996). Entry characteristics, practice variables, and cognition: Student mediation of instruction. Journal of Teaching in Physical Education, 15, 135-150.

Spielberger, C.D., \& Starr, L.M. (1994). Curiosity and exploratory behavior. In H.F. O'Neil, Jr., \& M. Drillings, (Eds.), Motivation: Theory and research. Hillsdale, NJ: LEA.

Spray, C.M., \& Biddle, S.J.H. (1997). Achievement goal orientations and participation in physical education among male and female sixth form students. European Physical Education Review, 3, 83-90.

Spray, C.M., Biddle, S.J.H., \& Fox, K.R. (1999). Achievement goals, beliefs about the cause of success and reported emotion in post-16 physical education. Journal of Sports Sciences, 17, 213-219.

Stipek, D.J. (1996). Motivation and instruction. In D.C. Berliner \& R.C. Calfee (Eds.), Handbook of Educational Psychology (pp. 85-113). New York: Macmillan.

Theeboom, M., De Knop, P., \& Weiss, M. (1995). Motivational climate, psychological responses, and motor skill development in children's sport: A field-based intervention study. Journal of Sport \& Exercise Psychology, 17, 294-311.

Tobias, S. (1995). Interest and metacognitive word knowledge. Journal of Educational Psychology, 87, 399-405. 
Treasure, D.C. (1997). Perceptions of the motivational climate and elementary school children's cognitive and affective response. Journal of Sport \& Exercise Psychology, 19, 278-290.

Treasure, D.C., \& Roberts, G.C. (1994). Cognitive and affective concomitants of task and ego goal orientations during the middle school years. Journal of Sport \& Exercise Psychology, 16, 15-28.

Urdan, T.C. (1997). Achievement goal theory: Past results, future directions. In M.L. Maehr \& P.R. Pintrich (Eds.), Advances in motivation and achievement Vol. 10 (99-141). Greenwich, CT: JAI Press.

Urdan, T.C., \& Maehr, M.L. (1995). Beyond a two-goal theory of motivation and achievement: A case for social goals. Review of Educational Research, 65, 213-243.

Urdan, T., Midgley, C., \& Wood, S. (1995). Special issues in reforming middle level schools. Journal of Early Adolescence, 15, 9-37.

U.S. Department of Health and Human Services. (1996). Physical activity and health: A report of the Surgeon General. Atlanta, GA: U.S. Department of Health and Human Services, Centers for Disease Control and Prevention, National Center for Chronic Disease Prevention and Health Promotion.

Van Wersch, A., Trew, K., \& Turner, 1. (1992). Post-primary school pupils' interest in physical education: Age and gender differences. British Journal of Educational Psychology, 62, 56-72.

Vlachopoulos, S., \& Biddle, S.J.H. (1997). Modeling the relation of goal orientations to achievement-related affect in physical education: Does perceived ability matter? Journal of Sport \& Exercise Psychology, 19, 169-187.

Walling, M.D., \& Duda, J.L. (1995). Goal and their associations with beliefs about success in and perceptions of the purpose of physical education. Journal of Teaching in Physical Education, 14.140-156.

Wentzel, K.R. (1989). Adolescent classroom goals, standards for performance, and academic achievement: An interactionist perspective. Journal of Educational Psychology, 81, 131-142.

Xiang, P., \& Lee, A. (1998). The development of self-perceptions of ability and achievement goals and their relations in physical education. Research Quarterly for Exercise and Sport, 69, 231-241. 